\title{
Innocent Suspects Lying by Omission
}

\author{
Kevin $\mathbf{C}^{1^{*}}$, Amina $\mathbf{M}^{2}$, Neslihan $\mathrm{JK}^{1}$, Molly $\mathbf{M}^{1}$, Emily $\mathbf{W}^{1}$, Lindsey $\mathbf{C}^{3}$ and Barry $\mathrm{C}^{4}$
}

${ }^{1}$ Department of Psychology, Southern Connecticut State University, Connecticut, US

${ }^{2}$ Department of Psychology, Royal Holloway University of London, London, UK

${ }^{3}$ Department of Psychology, University of New Hampshire, New Hampshire, US

${ }^{4}$ Department of Psychology, Simon Fraser University, British Columbia, Canada

*Corresponding Author: Kevin Colwell, Department of Psychology, Southern Connecticut State University, Connecticut, US, Tel: +441784276563; E-mail: colwellk2@southernct.edu

Received date: February 06, 2018, Accepted date: February 09, 2018, Published date: February 13, 2018

Copyright: (C) 2018 Kevin C, et al. This is an open-access article distributed under the terms of the Creative Commons Attribution License, which permits unrestricted use, distribution, and reproduction in any medium, provided the original author and source are credited.

\begin{abstract}
When, and under what conditions, do innocent people lie to investigators? This research was inspired by two cases where innocent suspects omitted the truth and came under suspicion. In a simulation of a theft from a faculty break room, participants were either told (1) not to take anything (no transgression innocent, NTI); (2) to commit a minor social transgression (social transgression innocent, STI ) or (3) to remove a wallet (guilty participants). Student investigators were presented with a photo suggesting guilt and were asked to interview each participant about her or his actions. Seven of 30 in the STI group chose to omit the transgression during the investigation (STIO). Those in the STI-O group appeared as guilty to investigators as the Guilty group, and guiltier than the STI and NTI groups. This omission fits with self-presentational concerns of innocent people to create a favorable impression and avoid suspicion. This behavior can impact police investigations and influence false confessions.
\end{abstract}

Keywords: Innocent; Investigation; Guilty; People

\section{Introduction}

False confessions and wrongful convictions draw worldwide attention. In the USA, for example, DNA testing exonerated 342 wrongly-convicted individuals [1] and, in approximately 30 percent of cases it, false confessions led to convictions [2]. In Sweden, Sture Bergwall confessed to 30 serial killings, and years later it came to light that he had fabricated these accounts [3] and miscarriage of justice cases have also arisen in Japan [4]. Once provided, confessions are compelling forms of evidence [2,5]. In two studies of juror decision making, found that even when DNA evidence excluded the confessor, confessions could still result in a 3 -fold increase in votes for conviction [5].

Popular approaches to interrogation training [6] often equate deception with guilt, and lean heavily towards eliciting a confession. The police-as with most people-are not good at detecting deception [7]. Approaches to investigative interviewing and credibility assessment presume that innocent people will respond honestly and completely. This paper is concerned with how an innocent suspect behaves when they have something other than the crime in question that they do not want to reveal, and how this behavior can increase apparent guilt. In the real world, this apparent guilt can lead to the interrogation of an innocent person, and create risk of a false confession [2]. This study was designed as the result of the following two cases from the State of Texas. In each, the suspect: A) lied to hide something, B) the investigator(s) detected this deception and C) presumed that the suspect was guilty. This led the investigator(s) to switch from interviewing to interrogation, and then use the evidence of the deception to manipulate the suspect into believing that she would appear guilty to the judge and jury. The deception became part of a sequence that ultimately led to a false confession. A through $\mathrm{C}$ is to be the focus of the laboratory portion of this work, although the entire chain presents a new pathway to false confessions, and is ripe for further research.

In the first case, The State of Texas versus Tamika Andrews, Ms. Andrews, a nanny allegedly allowed injury to the child in her care. According to the transcript of the interrogation, she provided the detectives with two conflicting accounts that did not fit the facts leading to an interrogation. This led to an interrogation where Ms. Andrews was told a physician was planning to report that Ms. Andrews had caused the observed injuries in a case of, "Shaken Baby Syndrome." Ms. Andrews initially denied shaking the child. However, after half an hour of being forced to shake a doll in imitation of how the detectives determined the injuries must have happened, she confessed. Upon being charged with First Degree Felony Assault, Ms. Andres recanted her confession. The case went to trial, and in a strange turn of events, she confessed to Reckless Injury to a child. The court accepted the confession, and she received 10 years of probation [8]. Post-trial, Ms. Andrews spontaneously reported what she claimed was the truth, an account validated by two witnesses and a recording in the Laundromat. Ms. Andrews propped the child up on a laundry table. The child fell headfirst, with the weight of her body and the carrier. This caused the child to have a seizure, and the damage that was misinterpreted as, "shaken baby syndrome." As Attorney Davis said, "If only she had known that she could produce witnesses, she wouldn't have confessed to anything, and she could have told the truth.

In the second case, State of Texas v. Carolina Pavon, a child too young to walk somehow got her leg broken. The detective had taken telephone statements from other suspects prior to interviewing Mrs. Pavon. These other suspects allegedly stated that Mrs. Pavon conducted an indigenous Mexican healing ceremony on the child's injured leg. Mrs. Pavon omitted and then initially denied that she had performed this healing ceremony. The detective characterized her as, "a 
liar," and gave the impression that deception regarding the healing ceremony was the same as deception regarding child abuse [9]. There are several reasons why Mrs. Pavon may have chosen to hide the healing ceremony. First, the healing could have been to cover up child abuse. Second, the healing marked Mrs. Pavon as lower in social standing than the detective within the Mexican-American community of Texas (during the trial, the Detective scoffed at this ritual, and called it, "voodoo."). Third, even if the healing was for empathy and kindness, Mrs. Pavon could have been fearful regarding how it would be seen.

Once this deception was broached, the detective moved from an investigative interview to an interrogation [9]. According to the report from the expert for the Defense, the detective was "Deceptively implying that confessing to child abuse was the best thing for the suspect to do in order to remain in the US and retain custody of her own children". Mrs. Pavon confessed to 5 different versions of the crime, agreeing to whatever scenario the detective provided. Later, she recanted her confession(s), and went to trial. She was found not guilty. Despite this, she was deported to Mexico.

In both cases the women engaged in impression management in order to be seen in a favorable light [10]. Each woman tried to hide a portion of her behavior, thinking that this would make her appear more innocent, but she actually left vital evidence unexplained and increased perceived guilt. This was exacerbated by investigator bias.

How often and, under what circumstances, would an innocent person lie during an investigation? What impact do these lies have on the perceptions of investigators? Based on these two cases and the aforementioned research we hypothesize that innocent people who have committed a social transgression will lie by omission more often than those who have not committed a social transgression. We also hypothesize that those innocent people who lie by omission will be more likely to be perceived as guilty by investigators than those innocent people who did not lie by omission.

\section{Method}

Ninety participants from a university in the Northeastern United States-58 women and 32 men-took part in the present study. The mean age was 24 years ( $\mathrm{SD}=1.4$ years). According to self-report, $47 \%$ of the sample were European or European-American, 28\% were African or African-American, $17 \%$ were Hispanic, $6 \%$ were Asian or AsianAmerican, and 2\% were, "other." All procedures were in compliance with the university's Institutional Review Board.

Three students who were blind to the hypotheses served as the investigators. They had no knowledge of the literature regarding investigative interviewing, credibility assessment, or impression management. They each received 3 hours of Psychology course credit for their work on this study.

Participants were recruited for what was ostensibly a study on memory under conditions of anxiety. Participants met with a Research Coordinator (RC) who informed them that they would be required to "sneak" into a break room just down the hall from the Psychology Department main office. There was a large sign on the door that read "Faculty Break Room-No Students." The participants were further deceived to believe that the faculty and staff did not know about the study, and that any student caught in the break room would have to find the PI of the study to "get the out of trouble." The potential trouble was left ambiguous. The participants were videotaped while in the room to monitor their behavior and provide evidence for the investigator in the forthcoming interview.

The Research Coordinator RC randomly assigned the participants into three groups of 30 as follows: 1) No Transgression Innocent (NTI), 2) Social Transgression Innocent (STI), and 3) Guilty. The NTI group was instructed to search the room as part of a memory experiment. They were told to search through the cabinets and drawers in the room, and attempt to remember as much as they could. The STI received identical instructions, with the addition that they were to find and, "take," an envelope that had the name of the Principle Investigator (PI) on it. This envelope contained money that could be seen, and it appeared to have several more bills besides the visible one. The Guilty group received identical instruction, with the exception that they were supposed to find and, "steal," a wallet. The wallet had several cards with the name of the PI, and \$20 in cash inside.

The study was deliberately set up so that taking the envelope could make the participant believe that they would be under increased suspicion during the forthcoming investigation regarding the theft of the wallet. First, the envelope was covered by the wallet, so to describe taking the envelope completely, a participant would have to mention touching or moving the wallet. Second, we hoped that the participants would believe that reporting taking an envelope with money would arouse suspicion that they also took a wallet with money. Third, taking anything from this room could be perceived as a transgression. Fourth, the envelope had the name of the PI on it in the recipient's location, so that it was obviously something that did not belong to the participant.

The NTI and STI groups were instructed to answer as honestly and completely as possible. It was emphasized to these groups that the purpose of the investigation was to find the person who stole the wallet the PI's wallet, and that those who were innocent should respond honestly. In contrast, the Guilty group was instructed to lie so that the investigator would not think that they had taken the wallet.

All participants reported back to the RC upon completion of their $\operatorname{task}(\mathrm{s})$ in the break room. The RC verified that participants did as they had been instructed by asking whether they attempted the required survey of the room, and by receiving the envelope or wallet when appropriate. The RC was under strict instructions to not allow the participants to practice describing the items in the room. Following this, the RC gave each participant a "pep talk," explaining the importance of appearing innocent to the investigator. They were reminded that, in the real world, they would be facing potential charges and jail time, and the quality of the data in this experiment depended upon treating the investigator just as they would treat a real police officer. Participants were told that those who were perceived as "innocent" by the investigator would win $\$ 2$. Finally, they were told that the two participants who were rated "the least likely to have stolen the wallet," would each win $\$ 100$. At this point, participants were required to repeat their instructions back to the RC. Following the, "pep talk," participants were told to, "Take a few minutes to plan what you are going to say."

All participants should have been aware that the theft of the wallet was only a mock theft, and therefore the primary motivating factor should have been a chance to win money rather than a need to avoid punishment. Ethical concerns prevented using a scenario in which the students would perceive themselves as genuine suspects in a manner that would provide adequate motivation. Therefore, incentive, rather than avoidance, was used as the motivating force. The goal of this process was to create a "double bind" situation where different portions 
of the instructions were in conflict. Responding completely and honestly is somewhat at odds with appearing as the least likely to have stolen the wallet. Further, the instruction to plan one's statement could be taken as implicit permission to distort or omit some details. This was hoped to create a situation that allowed insight into whether, and when, innocent people will deliberately distort of omit information during an investigation.

Interviews were recorded and transcribed. Each transcript was scored by undergraduate research assistants according to whether each participant followed their instructions. A participant from the NTI or STI group was scored as having followed instructions if their statement described what they were doing in the room during the memory study. A participant from the Guilty group was scored as having followed instructions if their statement made it appear that they had not taken the wallet. Each statement was coded by two undergraduate raters who were blind to the method and hypotheses of the study. The statements were rated as either Followed Directions $(F D)=0$, or Did Not Follow Directions $(\mathrm{NFD})=1$.

Each of these raters was provided with example statements manufactured by the first author to demonstrate the different categories (one that described taking the wallet, one that described taking the envelope and one that described neither). After seeing these examples, the two raters read and coded all of the statements. Overall, inter-rater agreement was $98.9 \%$, with a Kappa of .86 . We hypothesized that participants in the NTI and the Guilty groups would follow directions at a higher rate than the participants in the STI group (e.g., as those in the STI group were expected to be afraid that admitting to taking the envelope full of money could make them appear more likely to have been involved in the theft of the wallet).

The investigators were shown a picture taken by a hidden camera of each participant. This picture showed the participant reaching into the cabinet where the envelope and wallet were hidden. However, the camera was placed so that the opened door of the cabinet blocked the view of the participant's hands, as well as the contents of the cabinets. The investigators were told by the PI that the participants were almost certainly guilty, and that the picture proved it. We instilled a guilt bias for two reasons (1) to mirror what resulted in the omission of information in the cases described earlier and (2) to see if the adoption of an investigative interviewing style would override this bias. The investigators underwent half-day training on investigative interviewing and memory enhancement. They were instructed to follow the interview script, which was a version of the Cognitive Interview (CI) [11].

They were provided with a script of the CI, and practiced by interviewing each other. This script comprised the building of rapport, description of two innocuous events, a free narrative of the time spent in the room, transfer of control and a mental reinstatement of context followed by another narrative, recall from another perspective, reverseorder recall, and a retelling of the entire event. Finally, each interviewer conducted one practice interview during a pilot stage of this study.
Obviously, all investigators knew that this was a mock-theft scenario. They were told that money would be allotted to the participants on the basis of their decisions, in order to help motivate them. Each interviewer was instructed to listen carefully to determine whether the respondent adequately explained what they were doing in the cabinet where the wallet was stolen. The investigators' task was to determine guilt based upon whether the suspect's statement provided acceptable reasons for being in the room and going through the cabinet. These interviewers were not provided with any specialized information regarding the detection of deception or assessment of credibility. They were shown the picture of the participant opening the cabinet where the wallet had been, and told that if the participant was innocent she or he should provide an account that explained what they were doing in that cabinet. The implication was that if participant did not give a convincing account of what they were doing in the cabinet, they were lying and therefore guilty.

After the investigative interview ended, the RC entered the room and the Investigator left. Outside of the interview room, the investigator answered the following in written format - "Do you think this person stole the wallet, yes or No?" These responses were coded as Apparent Guilt, $0=$ Innocent, and 1=Guilty.

Inside the interview room, the RC provided the participants with a questionnaire. Those in the NTI condition were asked, "Did you tell the interviewer that you were in a memory study?" Those in the STI condition were asked, "Did you tell the interviewer that you took the envelope?" Those in the Guilty condition were asked, "Did you lie to conceal the fact that you took the wallet?" Those in the NTI and STI groups were presented with the following: "If you answered, "no," to the above question, please write a sentence explaining why you chose not to reveal all of your actions in the room to the investigator." Participants in the Guilty group were presented with the following: "If you answered, "yes," to the above question, please write a sentence explaining why you chose to reveal your actions in the room to the investigator." Taken together, this group of questions assessed the reasons why participants could choose to deviate from the instructions they were provided. In other words, they answered the question, "Why those in the STI group would choose to omit information?".

\section{Results}

Manipulation Check, The final item on the post-interview questionnaire was a manipulation check, which asked participants what they had been instructed to do during the interview. All of the participants except one checked item corresponding to their actual instructions. Also, all participants but one who were rated as NFD did so by omitting information about the envelope from their statement during the investigative interview. Therefore, it appeared that all but one participant genuinely understood the instructions and followed directions. Thus, the overall stimulus presentation and manipulation were successful.

\begin{tabular}{|l|l|l|l|l|l|l|}
\hline & \# Followed Directions & \# Not Followed Directions & \% Not Followed Directions & Standard Deviation & Standard Error & $95 \% \mathrm{Cl}$ \\
\hline NTI & 30 & 0 & $0.00 \%$ & $<0.01$ & $<0.01$ & $-1 \%, 1 \%$ \\
\hline STI & 23 & 7 & $23.30 \%$ & $4.30 \%$ & $7.90 \%$ & $7.3 \%, 39 \%$ \\
\hline
\end{tabular}


Citation: Kevin C, Amina M, Neslihan JK, Molly M, Emily W, et al (2018) Innocent Suspects Lying by Omission. J Foren Psy 3: 133. doi:

\begin{tabular}{|l|l|l|l|l|l|l|}
\hline Guilty & 29 & 1 & $3.30 \%$ & $18 \%$ & $3.30 \%$ & $-3.5 \%, 10.1 \%$ \\
\hline
\end{tabular}

Table 1: Participant's choices to follow directions by experimental condition.

To reiterate, raters coded participants' statements as $0=$ "Followed Directions," (FD) or 1="Did not Follow Directions," (NFD). It was predicted that participants in the STI group would be rated as NFD at a higher rate than participants in the other groups as a result of hiding information about taking the envelope. We further predicted that STI participants who omitted the envelope from their statements would be rated as Guilty more often than those STI participants who did not omit the envelope from their statement.

All participants in the NTI condition were rated as FD, as were 23 of 30 in the STI condition, and 29 of 30 in the Guilty condition (Table 1).

A Chi-Square analysis indicated a significant relationship between experimental condition and FD category, $\mathrm{X} 2(2, \mathrm{~N}=90)=11.8, \mathrm{p}<0.01$.
To understand where the differences in FD across conditions, JASP software was used to conduct Bayesian binomial tests, with prior parameters set to the default for the program. According to these, there was strong evidence that the participants in the STI group less likely to be rated FD than the participants in either the NTI or Guilty groups (Table 2). The odds of a participant in the STI group being rated as FD were 19.47 times lower than the odds of a participant in the NTI group, and 8.83 times lower than for participants in the Guilty group (Table 2).

\begin{tabular}{|c|c|c|c|c|c|c|c|}
\hline Condition 1 & \# FD & $\begin{array}{l}\text { Proportion } \\
(95 \% \mathrm{Cl})\end{array}$ & Condition 2 & \# FD & $\begin{array}{l}\text { Proportion } \\
(95 \% \mathrm{Cl})\end{array}$ & $\begin{array}{l}\mathrm{BF}_{+0} \\
\mathrm{BF}_{0+}\end{array}$ & $\begin{array}{l}\text { Odds Ratio } \\
(95 \% \mathrm{Cl})\end{array}$ \\
\hline STI & $23 / 30$ & $\begin{array}{l}0.77 \\
(0.61,0.93)\end{array}$ & $<\mathrm{NTI}$ & $30 / 30$ & $\begin{array}{l}1 \\
\text { (na, na) }\end{array}$ & $\begin{array}{l}356.52^{\mathrm{a}} \\
1.57 \times 10^{-7}\end{array}$ & $\begin{array}{l}19.47 \\
(1.06,358.40)\end{array}$ \\
\hline STI & $23 / 30$ & $\begin{array}{l}0.77 \\
(0.61,0.93)\end{array}$ & $<$ Guilty & $29 / 30$ & $\begin{array}{l}0.97 \\
(0.90,1.03)\end{array}$ & $\begin{array}{l}39.67^{\mathrm{b}} \\
0.03\end{array}$ & $\begin{array}{l}8.83 \\
(1.01,76.96)\end{array}$ \\
\hline
\end{tabular}

Table 2: Bayesian Binomial Tests comparing rates of Following Directions.

There are 2 Bayes Factors reported in the tables of this study. BF ${ }_{+0}=\left(\right.$ likelihood of $\left.\mathrm{H}_{1}\right) /\left(\right.$ likelihood of $\left.\mathrm{H}_{0}\right)=$ likelihood of the alternative hypothesis relative to the null hypothesis, given the observed data. $\mathrm{BF}_{0+}=\left(\right.$ likelihood of $\left.\mathrm{H}_{0}\right) /\left(\right.$ likelihood of $\left.\mathrm{H}_{1}\right)$ =likelihood of the null hypothesis relative to the alternative hypothesis, given the observed data [12]. This ability of Bayes factors to provide indicate relative likelihoods of both the alternative and the null hypotheses is one of their many advantages [13]. Bayes factors can be interpreted as ratios. However, useful benchmarks to describe the strength of evidence associated with BF values were provided by Jeffreys (1961; as described in [13]. - Anecdotal (1-3), Substantial (3-10), Strong (10-30), Very Strong (30-150), and Decisive (>150).

The ratings of FD versus NFD split the STI group, to create the quasi-experimental conditions of STI-No Omission, and STIOmission. The 7 participants in the STI-Omission group were asked to provide their reasons for omitting information about taking the envelope full of money. These reasons are provided, verbatim, in (Table $3)$.

\begin{tabular}{|c|l|}
\hline Participant & \\
\hline 1 & I did not want her to know that I moved the wallet off of the envelope. \\
\hline 2 & The interviewer did not need to know about that. \\
\hline 3 & It seemed like I was up to something, taking the envelope out of the cabinet. It didn't sound good. Especially since it was full of money. \\
\hline 4 & Leaving with the envelope was like stealing. So I didn't tell her. \\
\hline 5 & I did not want to seem like I would just take something. Maybe he would think I went back and took the wallet later. \\
\hline 6 & The wallet and the envelope were right next to each other, and I didn't want to get into all of that. \\
\hline 7 & I wasn't supposed to be in there taking things at all. \\
\hline
\end{tabular}

Table 3: Reasons for omitting the envelope provided by the STI-Omission participants. 
Page 5 of 6

The first step in analyzing the Apparent Guilt data provided in Table 4 was to determine whether there is a difference in Apparent Guilt across quasi-conditions. A Chi Square analysis indicated a relationship between quasi-condition (STI-No Omission, STI-Omission, NTI, and Guilty) and Apparent Guilt, X2 (3, N=90) = 16.4, p<0.01 (see Table 4 for Odds Ratios).

To determine the precise nature of this relationship, the Apparent Guilt of the STI-Omission condition was compared to the Apparent Guilt of each of the other conditions using Bayesian Binomial Tests, again with prior parameters set to the default for JASP software (Table 4). There was decisive evidence that the STI-Omission group was more likely to be rated Guilty than either the NTI group or the STI-No Omission group. The odds for being rated Guilty were 16.51 time higher for a participant in the STI-Omission group than for a participant in the NTI group and 13.71 times higher for a participant in the STI-Omission group than for a participant in the STI-No Omission group. Conversely, there was strong evidence that the STIOmission group was no less likely to be rated Guilty than was the Guilty group (Table 4). The odds for being rated Guilty were 3.0 times higher for a participant in the STI-Omission group than they were for a participant in the Guilty group (Table 4). Overall, these analyses indicated that the STI-Omission group were more likely to be rated as Guilty than were the other innocent suspects, and just as likely to be rated guilty as the guilty suspects. Importantly, the statements in the STI-Omission group (mean \# of words $=387, \mathrm{SD}=147$ ) contained just as many words as the statements of the STI-No Omission group (mean \# of words $=394, \mathrm{SD}=84$ ). The statements from the STI-Omission group were detailed, with the specific strategic omission of the envelope. The omission of the envelope was due to incomplete statements from unmotivated participants.

\begin{tabular}{|c|c|c|c|c|c|c|c|}
\hline Condition 1 & $\begin{array}{l}\text { \# App. } \\
\text { Guilty }\end{array}$ & $\begin{array}{l}\text { Proportion } \\
(95 \% \mathrm{Cl})\end{array}$ & Condition 2 & $\begin{array}{l}\text { \# App. } \\
\text { Guilty }\end{array}$ & $\begin{array}{l}\text { Proportion } \\
(95 \% \mathrm{Cl})\end{array}$ & $\begin{array}{l}\mathrm{BF}_{+0} \\
\mathrm{BF}_{0+}\end{array}$ & $\begin{array}{l}\text { Odds Ratio } \\
(95 \% \mathrm{Cl})\end{array}$ \\
\hline STI-Omission & $6 / 7$ & $\begin{array}{l}0.86 \\
(.57,1.15)\end{array}$ & $>\mathrm{NTI}$ & $8 / 30$ & $\begin{array}{l}0.27 \\
(0.11,0.43)\end{array}$ & $\begin{array}{l}1.31 \times 10^{11 a} \\
0.85\end{array}$ & $\begin{array}{l}16.51 \\
(1.71,159.14)\end{array}$ \\
\hline STI-Omission & & $\begin{array}{l}0.86 \\
(.57,1.15)\end{array}$ & >STI-No Omission & $7 / 23$ & $\begin{array}{l}0.3 \\
(0.10,0.50)\end{array}$ & $\begin{array}{l}2.61 \times 10^{7 a} \\
3.84 \times 10^{-8}\end{array}$ & $\begin{array}{l}13.71 \\
(1.39,132.22)\end{array}$ \\
\hline STI-Omission & & $\begin{array}{l}0.86 \\
(.57,1.15)\end{array}$ & $<$ Guilty & $20 / 30$ & $\begin{array}{l}0.67 \\
(0.50,0.85)\end{array}$ & $\begin{array}{l}0.12 \\
8.13^{b}\end{array}$ & $\begin{array}{l}3 \\
(.32,28.44)\end{array}$ \\
\hline
\end{tabular}

Table 4: Bayesian Binomial Tests comparing rates of Apparent Guilt.

\section{Discussion}

The current study presents a new pathway that can help us understand deception and false confessions among innocent suspects. This pathway begins when an innocent person chooses to lie to an investigator by withholding information. This deception through omission is detected, and the investigator then believes that the innocent person is guilty (after all, why would they lie if they are innocent?). In the real world this could cause an investigator to move into an interrogative style of interviewing putting an innocent person at risk. The convergence between this research, and the original cases which spawned it, creates a compelling argument that innocent people sometimes lie to investigators, omitting details that could be relevant, and that could exonerate them. This is a significant finding given that much police training has been built upon the following premises: Firstly, that innocent people will be forthcoming, and secondly, that deception is an indicator of guilt. These assumptions, especially if there are investigator biases, result in a tendency toward suspicion whenever statements are discrepant with 'known facts.' Even investigators with truth seeking [14] likely would be suspicious when details are deliberately omitted.

About one innocent student in four in our study failed to report a suspicious activity that they engaged in (they took an envelope that contained money). This social transgression was omitted in spite of directions to respond honestly, presumably due to fear of incrimination. Participants had not merely forgotten what they did, this was a deliberate strategy motivated by self-presentation. According to [15] the two main motives are to please the audience and to construct one's public self-image so that it fits the ideal. Applying this theory to the current domain [16] and others $[10,17,18]$ have suggested that both liars and truth tellers are similarly motivated to achieve a favorable impression and appear credible. Similarly, advocates of interpersonal deception theory [19] speculate that communicators may decide honesty is not the best policy and will be motivated to create a favorable impression by obscuring information.

This research suggests that self-presentational concerns and perceived external pressures interact to determine the reporting strategy employed during an investigative interview. For example, a guilt bias from an investigator, and the associated pressure to confess, could heighten self-presentational concerns to appear innocent, and thereby lead innocents to lie. There may be particular situational and individual difference variables that could increase tendency to be less than forthcoming in an interview. There is a gap in our knowledge here but some indication from studies of vulnerability in suspect interviews show that insecure attachment styles, low self-esteem and neuroticism could play a part [20].

There is, at first, an apparent contradiction between these data and previous studies. Researchers have reported honest respondents tend to believe that their behavior is transparent and their honesty is evident [21], and that simply telling the truth would be sufficient to be exonerated. Indeed, this is apparently the belief that an innocent Stephen Avery, who spent 22 years in prison for rape, clung to [22]. However, the deception detection literature clearly indicates that honesty is far from transparent to observers [23].

For the minority who chose to omit their transgression, the reasons provided in Table 3 point to a fear that disclosing the taking of the envelope to the investigator could lead to increased suspicion. The fact that each participant could provide a coherent reason for their omission is important in itself-it underscores the point that these 
omissions were deliberate rather than accidental. Each reason is pragmatic, and related to avoiding difficulty during the interview, or avoiding additional suspicion and potential blame. The majority of participants behaved as expected given that they were interviewed with a Cognitive Interview which encourages a detailed recall [11]. Investigators need to be aware however that they cannot always rely on detail as an indication of whether a witness is lying or telling the truth. Real cases where innocent suspects have come up with rich confessions regarding crimes they did not commit $[2,3]$ serve as a powerful reminder.

The challenge for training is how to shift the mindset of investigators that deception is always indicative of guilt. Raising awareness of the many genuine reasons why someone may hide or obscure the truth, and letting the respondent tell their story, are starting points. Naturally, as circumstances change, as transgressions become more odious (for example committing a minor crime when being investigated for a major crime), respondents have increased reason to mistrust law enforcement (such as with the rise of social media showing police brutality), and as governments endorse so-called enhanced interrogation techniques [24], the rate of deception by omission will likely increase. It is becoming increasingly apparent that a 'relationship' based style of interviewing where investigators genuinely try and build a rapport with suspects can potentially yield more complete reports [25].

\section{Acknowledgments}

We thank Nick Furl for insightful comments and practical advice on an earlier draft and Edmund "Skip" Davis, J.D. for his help with this project and manuscript.

\section{References}

1. Peter N (2016) The innocence project, Non-profit organization, USA.

2. Kassin S (2015) Social psychology of false confessions, Soc. Issues Policy Rev 9: 25-51.

3. Rastam H (2013) Thomas quick: The making of a serial killer, Canongate Books, Payback Press, UK.

4. Wachi T, Watanabe K, Yokota K, Otsuka Y, Lamb M (2016) Japanese interrogation techniques from prisoners perspectives, Crim. Justice Behav 43: 617-634.

5. Gudjonsson G (2010) Police interrogations and false confessions: Current research, practice, and policy recommendations, American Psychological Association, USA.

6. Inbau FE, Reid JP, Buckley JP (2013) Essentials of the Reid technique (2 ${ }^{\text {nd }}$ edn), Jones \& Bartlett Publishers, US.
7. Colwell K, James-Kangal N, Hiscock-Anisman CK, Phelan V (2015) Should Police use ACID: Training and Credibility Assessments using Transcripts versus Recordings. J Forensic Psychol Pract 15 226-247.

8. State of Texas v. Tameka Andrews (2010) 427th Judicial District, Case Number D-1-DC-08-301099, Travis Country, US.

9. State of Texas v. Carolina Pavon (2010) 427th Judicial District, Case Number D-1-DC-10-301892, Travis Country, US.

10. Colwell K, Hiscock-Anisman C, Memon A, Woods D, Michlik P (2006) Strategies of impression management among deceivers and truth-tellers: How liars attempt to convince. Am J Forensic Psychol 24: 1-9.

11. Memon A, Meissner CA, Fraser J (2010) The Cognitive Interview: A meta-analytic review and study space analysis of the past 25 years. Psychol. Public Policy Law 16: 340-372.

12. Jeffreys H (1961) Theory of probability (3rd edn), Oxford University Press, UK.

13. Jaroz AF, Wiley J (2014) What are the odds? A practical guide to computing and reporting bayes factors. J Probl Solving 7: 2-9.

14. Masip J, Alonso H, Garrido E, Herrero C (2009) Training to detect what? The biasing effects of training on veracity judgments. Appl Cogn Psychol 23: $1282-1296$.

15. Baumeister R (1982) A self-presentational view of social phenomenon. Psychol. Bull 91: 3-26.

16. DePaulo, B. (1992) A self-presentational view of social phenomenon. Psychol. Bull 111: 203-243.

17. Hartwig M, Granhag P, Stromwall L, Doering N (2010) Impression and information management: On the strategic self-regulation of innocent and guilty suspects. Open Criminology 3: 10-16.

18. Hines A, Colwell K, Hiscock-Anisman C, Garrett E, Ansarra R, et al. (2010) Impression management strategies of deceivers and honest reporters in an investigative interview. Eur J Psychol Appl L 2: 73-90.

19. Buller D, Burgoon J (1996) Interpersonal deception theory. Commun. Theory 6: 203-242.

20. Drake K (2011) Why might innocents make false confessions? Psychologist, The British Psychological Society, UK.

21. Gilovich T, Savitsky K, Medvec V (1998) The illusion of transparency: Biased assessments of others' ability to read one's emotional states. J Pers Soc Psychol 75: 332-346.

22. Ricciardi L, Demos M (2015) Making a Murderer, Netflix, USA.

23. Vrij A, Granhag P, Porter S (2010) Pitfalls and opportunities in nonverbal and verbal lie detection. Psychol. Sci. Public Interest 11: 89-121.

24. Chwastiak M (2015) Torture as normal work: The bush administration, the central intelligence agency and "Enhanced Interrogation Techniques." Organization 22: 493-511.

25. Alison L, Alison E, Noone G, Stamitis E, Waring S, et al. (2014) The efficacy of rapport-based techniques for minimizing counterinterrogation tactics amongst a field sample of terrorists, Psychol. Public Policy Law 220: 421-430. 